This is the peer reviewed version of the following article:

Zarantonello L., Romani S., Grappi S., Fetscherin M. (2018). Trajectories of brand hate. Journal of Brand Management. https://doi.org/10.1057/s41262-018-0105-5

The final publication is available at: $\underline{\mathrm{https}} / / /$ link.springer.com/article/10.1057/s41262-018-0105-5

This article may be used for non-commercial purpose $\mathrm{s}$ in accordance Springer Terms and Conditions for self-archiving.

\title{
Trajectories of brand hate
}

Taking inspiration from the work of Langner et al. (2016), this paper explores how the feeling of brand hate develops over time. To that aim, the paper conducts a series of qualitative interviews during which participants are asked to graphically trace the course of their feelings towards their most currently hated brand. In doing so, the paper identifies five types of trajectories of brand hate: "Negative all the way", "Down-up", "Downward slope flattens", "Roller coaster", and "Steady decrease". Moreover, it identifies the most common antecedents (i.e. negative past experience with the brand, corporate wrongdoing, and image incongruence) and outcomes of brand hate and relates them to the trajectories previously identified. Theoretical and managerial implications are discussed.

Key words: Brand hate; consumer emotions; consumer-brand relationship; qualitative analysis. 


\section{Trajectories of brand hate}

\section{INTRODUCTION}

The marketing literature has given a lot of attention to the phenomenon of positive emotions consumers have with brands, from brand liking (e.g., Spears and Singh, 2004) to brand passion (e.g., Albert et al., 2013), brand devotion (e.g., Pichler and Hemetsberger, 2007), and brand love (e.g., Albert et al., 2009; Batra et al., 2012; Carroll and Ahuvia, 2006; Rossiter, 2012). However, the spread and relevance of negative consumer-brand relationships have also been noted (Fournier and Alvarez, 2013). Given the importance of these relationships, scholars have started to examine negative emotions towards brands (Romani et al., 2012), such as brand aversion (Park et al., 2013), brand detachment (Perrin-Martinenq, 2004) and, more recently, brand hate (Alba and Lutz, 2013; Bryson et al., 2013; Fetscherin and Heinrich, 2014; Hegner et al., 2017; Grégoire et al., 2009; Johnson et al., 2011; Romani et al., 2015; Zarantonello et al., 2016). Brand hate, in particular, has been defined as an emotional construct with specific antecedents and outcomes on consumer behavior (e.g., Hegner et al., 2017; Zarantonello et al., 2016). Although these studies represent an important step forward in conceptualizing this extreme negative emotion to brands, they have mainly treated brand hate from a static perspective, thus paying not enough attention to the evolving nature of the phenomenon of hate (Sternberg, 2003). Taking this aspect into account could lead to a better understanding of brand hate, as has recently been achieved in the context of brand love (Langner et al., 2016).

The purpose of this study is twofold: First, to understand trajectories of brand hate by asking respondents their feeling for a brand in the past, present and future; second, to understand how these trajectories are related to the antecedents of brand hate and, most importantly, to the 
outcomes of brand hate. To do so, using a method similar to that of Langner et al. (2016), the paper carries out an analysis of consumers' trajectories of brand hate through qualitative interviews, supported by visual representations of the brand hate relationship from the first contact with the brand through to the current feelings and the future.

Although it uses a similar methodology, the current paper complements Langner et al.' contribution (2016) in two ways. First, the central point of this paper is brand hate and not brand love. As the psychology literature shows, hate is, after love, the second most prototypical emotion (Fehr and Russell, 1984) and among the most negative ones (Shaver et al., 1987). Therefore, it contributes to a better understanding of this important, yet different construct. Second, whereas Langner and colleagues (2016) focus on past and present, the current paper includes three points in time, namely, past, present, and future. The latter point was included in order to explore the possibility that brand hate leads to neutral feelings, like, or even love.

In the following, the paper first reviews the concept of brand hate. Then it presents the qualitative study and explains the possible types of brand hate trajectory, as well as how these trajectories relate to the antecedents and outcomes of brand hate. Finally, the paper discusses the implications of the study, as well as its limitations, and suggests directions for future research.

\section{THEORETICAL BACKGROUND}

\section{Relationship between love and hate}

The debate about the relationship between love and hate has been going on for centuries. As Solomon and Stone (2002, p. 418) stated, "the positive-negative polarity as well as the conception of emotional opposites have been origins in ethics, not in the scientific study of emotion $[\ldots]$ the notion of opposite comes out of the medieval church which in turn traces its 
psychology back to Aristotle". Turning now to the psychology literature, there are two schools of thought about the relationship or link between love and hate. One school argues that love and hate are not the opposite. They argue "the opposite of love may not be hate, since the two feelings can coexist, and one can love some things about one's partner and hate others at the same time" (Sprott, 2004, p. 304). The other school of thoughts argues that love and hate are polarities of emotions or "opposites" where both, love and hate, are extreme opposite emotions. Furthermore, Sternberg (2003, p. 13) states "hate is neither the absence of love nor its opposite, as is widely believed. However, love and hate are closely related psychologically to one other, which may be seen in the astonishing ease with which love relationship can be transformed into hate". His conceptualization of the triangular of love (1986) or hate (2003) suggest that both have similar but opposite emotional components. The second school of thought does not contradict that both love and hate can co-exist, but mainly argues that these feelings are the most extreme emotions in either the positive or negative.

\section{Brand hate}

In the marketing literature, brand hate has been examined by various scholars. Some of them focus on the antecedents or outcomes of brand hate, whereas others focus on the construct itself. In addition, some of these contributions include an empirical investigation of the brand hate construct, whereas others consist in developing a conceptual framework for hate and related phenomena.

Specifically, Grégoire et al. (2009) investigate the construct of consumer hate towards brands in the context of service brands. The authors look at brand hate from the viewpoint of its outcomes, as they treat it as consumer desire for revenge and consumer desire for avoidance. 
These two desires represent different manifestations of brand hate which can arise separately or jointly in consumers. Whereas the desire for revenge is associated with consumer need to punish and cause harm to firms for the damages they have caused, the desire for avoidance refers to consumer's need to withdraw from any interactions with the firm.

Later, Johnson et al. (2011) examine the effect of different types of prior consumer-brand relationships on anti-brand actions. Hate, or "hatred" as they call it, is one of the outcomes they take into account in their work. They operationalize hate in a consumer-brand relationship perspective, as a strong opposition to brands mainly represented by the concept of revenge. Examples of their hatred scale items include "The brand is my enemy", "I am a fanatic against this brand" and "It would please me to know I have inflicted harm on the firm that makes this brand". They also show that the emotion of shame acts as an important mediator in the process that brings consumers to behave hatefully.

Romani et al. (2012) treat hate towards the brand as an emotion descriptor in their construct of negative emotions towards brands. In particular, they view the feeling of hate as part of the dislike construct, together with the feeling of contempt and the feeling of revulsion. In their work, they show that dislike for brands, and therefore hate, is associated with complaining, negative word-of-mouth, and brand switching behaviors.

With regards to luxury goods, Bryson et al. (2013) provide a definition of brand hate as an intense negative emotional affect consumers experience towards the brand. They also identify possible causes for brand hate, including the brand's country of origin, consumer dissatisfaction, negative stereotypes of a brand's consumers, and corporate social performance.

In a conceptual paper, Alba and Lutz (2013) define "brand hatred" as "true brand disgust" (p. 268). Brand hatred is used to describe a situation where the consumer is "held 
hostage" by the company, for example, because of high switching costs, a local monopoly or some other manifestations of exit barriers. The results of this hatred are expressions of consumer's frustration via social media, postings on hate sites on the Internet and communicating negative affect in daily interactions with other consumers.

In an empirical study, Romani et al. (2015) show that brand hate feelings, conceptualized as contempt, anger/fear, and disgust, can be triggered by perceptions of moral violations of the brand parent company, and can result in anti-brand actions. In addition, they find that the level of hate felt by consumers depends on their empathy: the greater their level of empathy, the more the felt hate towards the brand of the company committing wrongdoings.

Zarantonello et al. (2016) conceptualize and operationalize brand hate as a constellation of negative emotions towards the brand, including anger, contempt, disgust, fear, disappointment, shame, and dehumanization. In their work, they find that brand hate is significantly associated with different negative behavioral outcomes, and that these vary depending on the reason for brand hate. Reasons for brand hate related to corporate wrongdoings and violation of expectations are associated with "attack-like" (i.e., negative WOM) and "approach-like" strategies (i.e., consumer complaining and protest behaviors), whereas reasons related to taste systems are associated with "avoidance-like" strategies (i.e., patronage reduction/cessation).

Finally, Hegner et al. (2017) define brand hate as "a more intense emotional response consumers have towards a brand than brand dislike" (p. 3), and empirically test its determinants and outcomes. Whilst the former include negative past experience, symbolic incongruence, and ideological incompatibility, the outcomes of brand hate include brand avoidance, negative wordof mouth, and brand retaliation. 
In sum, although the current literature shows a high degree of diversity in terms of conceptualizations and measures for brand hate, three main sets of antecedents for this construct can be definitely identified: (1) negative past experience with the product or service brand; (2) corporate wrongdoing as related to immoral, unethical, anti-social, or illegal corporate behavior; and (3) incongruence between the company brand image and self-image. These antecedents are associated with a variety of negative consumer behavior outcomes. Appendix A presents a summary of this literature.

\section{Trajectories of brand hate}

Previous contributions on brand hate achieved a "static" understanding of the concept, as they considered brand hate in one specific point of time. One exception in this sense is the work of Grégoire et al. (2009), who examine how consumers' desire for revenge and desire for avoidance develop over time. Results of their longitudinal studies show differences in the evolution of these two desires, confirming the usefulness of a non-static perspective in order to better understand consumers' negativity towards brands. However, their work focus on two outcome variables of hate, namely brand revenge and brand avoidance. In contrast, the aim of this paper is to advance the current understanding of changing of feelings for brands. The changing nature of brand love (Langner et al. 2016) in marketing has been investigated, whereas the changing nature of brand hate has not. In particular, Langner et al. (2016) found in their brand love study that the way the feeling of love evolves depends on the various formative experiences that consumers have gone through with a brand, and they identified five possible trajectories of brand love: (1) "Slow development," (2) "Liking becomes love," (3) "Love all the way," (4) "Bumpy road," 
characterized by an alternation of neutral and positive feelings towards the brand, and (5)

"Turnabout," characterized by both positive and negative feelings towards the brand.

Sternberg (2003) discusses the importance of acknowledging the changing nature of love as well as hate. He proposes to view both love and hate as stories, not as static images or stereotypes. Whereas the latter tend to be one-dimensional, immobile, and fixed over time, the former are multidimensional, fluid, and changeable. According to the psychologist, love and hate stories can be interrelated: for example, love stories can turn into hate stories because of the betrayal of the loved one, while hate stories can turn into love stories through understanding the target of hate. Although love stories tend to be more complex than hate stories, they both include three parts: (1) a beginning, (2) a middle, and, at times, (3) an end. In the case of hate, the beginning occurs when the target reveals itself to be deserving of hate for something it has done (e.g., negative actions against one's own group), or for some of its characteristics (e.g., dirtiness). The middle is characterized by the felt presence of the target of hate, its plans and actions against oneself or one's group, and its success in achieving its goals. The end of hate stories consists in the elimination of the target of hate from one's life, or in the reconciliation with the target of hate. Moreover, according to Sternberg, love stories that turn into hate include "seeds of destruction," that is, elements of different nature (e.g., individual psychological or external factors) that can undermine the relationship between the subject and what becomes the target of hate. These elements can result in negative, destructive experiences that can deteriorate the relationship in the long run.

Because of the relevant implications of Langner et al.'s (2016) contribution with respect to brand love, and considering the importance of viewing hate as a story (Sternberg, 2003), it is important to study trajectories of brand hate. To take into account the evolving nature of brand 
hate, the paper analyzes consumer trajectories of brand hate, in a manner similar to that of Langner et al. (2016).

\section{METHOD}

The paper adapts the method used by Langner et al. (2016) to investigate the changing nature of brand hate. A sample of 54 volunteer participants ( 22 male, 32 female, mean age $=28$ years) was involved in the study. All participants were living in Europe at the time of the interview, and about two thirds were university graduates or undergraduates.

Participants were interviewed individually. Interviews started with a question asking participants to name few brands they hated or towards which they felt extreme negative emotions. These two questions are consistent with the literature previously reviewed, which offers conceptualizations of brand hate in general, but also highlights the dimensionality of the brand hate construct and identify specific brand hate dimensions such as disgust for the brand (e.g., Alba and Lutz, 2013; Zarantonello et al., 2016). Then, participants were instructed to focus on the brand they hated the most and they were asked several questions about the selected brand. Namely, they were asked to: (i) recall and talk about their first contact with the hated brand and subsequent experiences; (ii) explain their reasons for hating the brand, which we then classified into the three antecedents of brand hate as discussed previously; (iii) describe the brand and their hate relationship with it; (iv) illustrate the behavior they adopted to express their hate towards the brand; and finally (v) talk about possible developments foreseen in the future. Interviews followed a semi-structured approach. The specific order questions were asked varied based on the specific dialogue and interaction with each participant. Follow-up and probe questions were also asked whenever necessary. 
In the last part of the interview, participants were instructed to sketch the pattern of their feelings towards the brand over time, making use of a template adapted from Langner $e t$ al. (2016) that assigned feelings towards the brand to the vertical axis (from the bottom upward: hate, dislike, neutral feelings, like, and love) and time to the horizontal axis (we included three points in time: past, present, and future). The sketch was accompanied by a verbal description, in which the participants summarized the evolution of their feelings towards the selected brand. Interviews were recorded and transcribed for analysis.

\section{ANALYSIS AND RESULTS}

\section{Types of brand hate trajectories}

The first part of the analysis consisted in the visual inspection of the trajectories sketched by participants and the coding of the interviews, which were useful to better understand the rationale behind the trajectories described by participants. Three researchers independently classified and coded the data collected. The inter-judge reliability of the coding was assessed using Rust and Cooil's (1994) proportional reduction in loss (PRL) index. The portion of interjudge agreement was computed (equal to 0.81). This value corresponded to a PRL of 0.97 (five categories and three judges; see Rust and Cooil, 1994, p. 12). As PRL is comparable to Cronbach's alpha (Rust \& Cooil, 1994), the value we obtained indicates a satisfactory interjudge reliability (Nunnally, 1978). Most importantly, no major issues were present among the researchers, who managed to resolve all conflicts and agree upon a coding.

On a general level, the analysis showed that the initial feeling for the brand was not necessarily the same for all the participants. A small number of participants $(\mathrm{N}=4)$ reported a negative feeling for the brand at the first contact, with half of them reporting a feeling of hate. 
However, the majority of the participants $(\mathrm{N}=31)$ had a positive feeling for the brand at the first contact, while about one third $(\mathrm{N}=19)$ were neutral at that stage. Because of these positive or neutral feelings at the beginning of the relationship with the brand, most of the trajectories sketched by the participants depict a worsening of the emotions towards the brand. How the relationship deteriorates varies from trajectory to trajectory: some show a steady decrease as negative feelings develop over time, whereas others show a sharp decrease at one particular point. On the other hand, some trajectories depict flat periods with no increase or decrease, while others suggest an increase in affection before the feeling worsens.

More specifically, the analysis revealed five possible types of brand hate trajectory, each characterized by a clear and distinct shape. We labelled these trajectories as "Negative all the way," "Down-up," "Downward slope flattens," "Roller coaster," and "Steady decrease." Each type of trajectory is described below and presented in Figure 1.

Insert Figure 1 about here

- Trajectory type 1: "Negative all the way" $(\mathrm{N}=17)$ describes a curve which lies entirely in the negative quadrant. In most cases $(\mathrm{N}=14)$, the trajectory begins with a neutral feeling which then turns into a negative feeling throughout, with peaks of hate. In a few cases $(\mathrm{N}=3)$, the trajectory includes only dislike and hate, with no neutral feelings. A typical description of the trajectory is the following: "At first my feeling for the (BP) brand was neutral ... After the catastrophe that happened 4-5 years ago, it dropped down... It kept going down further, when I saw that they weren't doing anything... Today I dislike them and am going to dislike them in the future" (participant \#4, male, 25 years). 
- Trajectory type 2: "Down-up" $(\mathrm{N}=14)$ describes a curve which decreases sharply and then goes up again. In most cases $(\mathrm{N}=12)$, it starts in the positive quadrant, but ends in the negative. In a few cases $(\mathrm{N}=2)$, it starts in the neutral zone. This trajectory describes a situation where the feeling for the brand has now dropped, but may pick up again in the future. By way of illustration, this is how one participant described her relationship with the brand: "At the beginning I was between neutral and like. I didn't really know much about the brand, but I thought it was cool and that is my first point of contact with it. After my first contact it kind of dipped to almost a hate relationship. I feel over time it will increase to a partial like" (participant \#21, female, 26 years).

- Trajectory type 3: "Downward slope flattens" $(\mathrm{N}=12)$ consists of a curve that goes from the positive to the negative quadrants, where it flattens out. The trajectory indicates, therefore, a worsening of the feeling towards the brand until it reaches a stable negative point. A typical description reads as follows: "In the past my feeling for the brand was like, love for the brand which continued until 4 or 5 months ago. Then, it went down drastically until it reached a feeling of hate, full hate. This is the relationship I will try to maintain with the brand in the future" (participant \#52, female, 26 years).

- Trajectory type 4: "Roller coaster" $(\mathrm{N}=6)$ describes a trajectory which, in the majority of cases $(\mathrm{N}=5)$, starts as a neutral feeling, then goes up and finally goes down; once down, the curve flattens. Only in one case does the trajectory start in the negative quadrant, but the pattern is the same (up and down again). The following is a typical description of this trajectory type: "My first contact with the brand was pretty neutral. It was alright. I was buying a new phone which would help me in so many ways. Then I started loving the brand, since it was my first smart phone. I was really happy. It had everything and every 
kind of stuff that you have in Apple today. It was pretty fun. Then, when the experience happened with the bad customer service, it broke down. They didn't give me a good customer support, so I started hating it and I will continue hating it" (participant \#17, female, 22 years).

- Trajectory type 5: "Steady decrease" $(\mathrm{N}=5)$ describes a curve which starts in the positive but then goes down all the way in the negative. The feeling towards the brand decreases throughout, from the past to the present, and then into the future. "At the beginning I thought the brand was pretty good. I kind of liked it, I had a good perception about it. Then I went to the store and I became neutral, not that good. Then at the second encounter with the brand I started to dislike it... I think my feeling for the brand will slightly decrease with time" (participant \#14, male, 23 years).

It is important to note that these trajectories are not brand- or product-dependent. Brands from different product categories were mentioned throughout the interviews. This is in line with research about brand love which suggest that love is not product category specific (Fetscherin et al., 2014). Overall, 120 unique hated brands from different product categories were mentioned during the interviews, with 44 unique brands being selected as the most hated ones (see Table 1 for details). Likewise, the trajectories of brand hate seems not to be gender-specific. Each category, in fact, includes both male and female participants.

Table 1 about here

\section{Antecedents and outcomes in brand hate trajectories}


The second part of the analysis focused on understanding the antecedents and outcomes associated with the trajectories of brand hate previously identified. In line with the current literature, the analysis revealed three sets of antecedents: negative past experience with the brand, corporate wrongdoing, and image incongruence. The former is associated with three trajectories ("Down-up", "Downward slope flattens," and "Steady decrease"), whereas the other two sets of antecedents characterize one trajectory each (respectively, "Negative all the way" and "Roller coaster"). The analysis also showed how the different antecedents affect the development of brand hate and its different outcomes. Overall, $67 \%$ of respondents reported having a negative past experience with the product or service brand, $36 \%$ reported the reason of their hate is corporate wrongdoing, and $26 \%$ mentioned image incongruence. Note, almost a third (32\%) of respondents mentioned more than one reason they hate the brand. For example, seven respondents mentioned negative past experience and corporate wrongdoing, three respondents mentioned negative past experience and image incongruence, and seven other respondents mentioned corporate wrongdoing and image incongruence as their reasons for hating the brand. Below we explain this in detail.

1. Negative past experience with the brand. Experiencing product or service failures in a consumer-brand relationship is the most recurrent reason mentioned by 67\% (36 respondents) of participants. It was the most mentioned reason for three trajectories of brand hate: "Down-up" (93\%), "Downward slope flattens" (82\%), and "Steady decrease" (80\%). Examples include new cars that did not perform according to participants' expectations: a Peugeot car that presented problems that customer service could not fix and for which the participant herself was blamed (participant \#30, female, 27 years); or Mercedes (participant \#36, male, 19 years) and Fiat (participant \#38, male, 60 years) cars that broke down several times, causing problems to 
participants' daily activities; or a Toyota car for which it was extremely difficult finding repair parts and that could not be used as needed (participant \#46, male, 20 years).

This antecedent can result into either negative or positive outcomes. Negative outcomes can be found in "Steady decrease" and "Downward slope flattens" trajectories, whereas positive outcomes characterize the "Down-up" trajectory. Specifically, in the "Steady decrease" trajectory, participants started using the brand as attracted by some aspects, such as low price (participant \#39, male, 21 years) or new flavor (participant \#8, male, 24 years). However, the more they used the brand, the more dissatisfied they became as they started noticing the poor quality of the products. Negative issues cumulated day after day without stopping, and the relationship with the brand took a turn for the worst: all participants bad-mouthed the brand and $20 \%$ of them complained with the company. Only one (participant \#23, male, 24 years) kept using the (Microsoft) brand, but simply because he could not avoid it due to its pervasiveness. None of the participants thought about reconciling with the brand in the future.

In the "Downward slope flattens" trajectory, participants experienced repeated product failures that led to a worsening of their feeling towards the brand until it reached a stable point. At that time they became disengaged with the brand and switched to other solutions. Only one participant (participant \#53, female, 26 years) reported using the (Pompea) brand in the present, as she still had not found a good alternative. All participants therefore reached a state of negative stability and became totally uninterested in the brand. About $90 \%$ of them adopted hateful behaviors, including complaining and negative word-of-mouth. For none of the participants a future reconciliation with the brand was possible.

In contrast, a positive outcome is sought after in the "Down-up" trajectory: $93 \%$ of respondents are open to buy the brand in the future, despite the negative feelings in the present. 
These openings to the brand are either consumer-based (for 33\% of participants) or brand-based (for $67 \%$ of participants). The former occurs if factors driving the future purchase of the brand are related to participants themselves, such as their willingness to pay lower prices (e.g., participant \#40, female, 40 years), participate in sales promotions (participant \#44, female 20 years), or receive the brand as a gift (participant \#29, male, 23 years). Brand-based openings, in contrast, occur when participants believe the external environment will force the brand to change its' behavior and adjust their offer (e.g., participant \#43, female, 19 years), or when participants are deeply attached to the brand and hope the brand will change in a positive way (participant \#42, female, 66 years). Because of this expected future outcome, participants in the "Down-up" trajectory voiced their dissatisfaction by adopting a more constructive approach: most of them (71\%) complained with the company, while some (57\%) bad-mouthed the brand.

2. Corporate wrongdoing. This was the second most significant reason for brand hate mentioned by $35 \%$ of participants ( 19 respondents). It was mostly found in the trajectory called "Negative all the way," and is related to unethical, immoral, anti-social or illegal issues. Examples of ethical issues, mentioned by $76 \%$ of participants in this trajectory, include BP's pollution (e.g., participant \#4, male, 25 years), Abercrombie \& Fitch's immoral recruiting practice (participant \#10, male, 22 years) and CEO's racist behavior (participant \#12, female, 26 years), McDonald's unhealthy lifestyle proposition (participant \#20, female, 25 years), and Walmart's violation of labor laws (participant \#19, female, 24 years).

Participants in this trajectory started their relationship with the brand either because they used it in the past (59\%) or simply after being exposed to it through different types of media (41\%). Sometimes the relationship started as neutral, as they did not know the brand, while with others it started as negative, because of the brand knowledge they already had. In any case, the 
more the participants learnt about the brand (e.g., how the brand behaves and what it stands for), the more they disliked and hated it. In fact, participants in this trajectory give importance to factors that are external to their (direct or indirect) experience with brands, such as social (i.e., other consumers using the brand) or environment/society factors (i.e., how the brand behaves in a wider context). This strong negative affect towards the brand results in a moral condemnation of the brand that leaves no hope for a positive future relationship. None of the participants is open or ready to forgive the brand in the future, as they believe that the reason why they hate the brand is part of the brand identity itself, therefore something that cannot really be changed. Their hate feeling is mainly expressed as rejection of the brand in the present and future, with about one third of participants (41\%) engaging in active hateful behaviors towards the brand or company behind.

3. Image incongruence. The third set of antecedent, which can be found in the "Roller coaster" trajectory relates mainly to the incongruence between consumers' self-image and brand image. This has been studied extensively in the marketing literature, where research (e.g., Birdwell, 1968; Bellenger et al., 1976) showed that image incongruence influences consumer's brand preference, purchase intention, and brand loyalty. Image incongruence can be of two types: either the company's brand image does not fit the self-image of the consumer, or the selfimage of the consumer does not fit the company's brand image. Participants had often ambivalent feelings towards the brand and reported to both love and hate the brand for different reasons.

To illustrate, one participant (participant \#18, male, 29 years) explained that he hated the Lonsdale brand mainly because of the people wearing it, that he does not like, and the meanings they associated to the brand, which he does not agree with. This exemplifies the type of 
incongruence where the company's brand image does not fit the self-image of the consumer. Another participant (participant \#50, female, 23 years) discussed her mixed emotions towards the Intimissimi brand. On the one side, she loves the brand, the imagery associated with it, its communications, the stores, and other brand's touch points. On the other side, she is not happy with the brand's products. She tried the brand several times but then abandoned it because products did not fit properly, because of her size. She felt frustrated about this situation, and would love the brand to consider people with her body type. The incongruence in this case results from her self-image not fitting the brand image of the company (the consumer is not able to wear the brand's product).

These ambivalent feelings result in conflicting relationships with the brand. All participants reported not using the brand in the present, as they switched to other solutions that they may like less but are easier to manage because they do not raise conflicts within participants. Although they claim they will not use the brand in the future, the majority of participants in this trajectory (67\%) engage in constructive hateful behaviors towards the brand, such as complaining with the company, in hopes of changing them in a way that is more aligned to their expectations and values to establish congruence between the company and the consumer.

\section{CONCLUSION}

\section{Theoretical contribution}

This paper contributed to the literature on brand hate in three ways. First, unlike previous studies, this paper investigated how consumers' feelings towards a brand changes in three points in time (i.e., past, present, and future). Second, the advantage of using a similar method as Langner et al. (2016) is it allows to compare our findings of brand hate with those of brand love. While the 
same graphical template was used, the trajectories are different. The main reason is Langner et al. (2016) study trajectories of brands consumers have positive feelings today. In contrast, this paper assesses trajectories of brands consumers have negative feelings today. Moreover, it provides an extension of the template by Langner et al. (2016) as 'future feeling' was added as another point in time allowing us to explore the possibility that brand hate could lead to neutral feelings, like, or even love. Third, it identified five unique and distinct trajectories of brand hate which can occur in consumer-brand relationships. Based on these trajectories, it identified the most common antecedents and outcomes of brand hate. Specifically, it showed that the trajectory "Down-up", "Downward slope flattens", and "Steady decrease" are influenced mainly by negative past experiences with the brand's product or services, and can result in both positive and negative outcomes. The trajectory "Negative all the way" is mostly influenced by corporate wrongdoing and is related to unethical, immoral, anti-social, or illegal behavior of the company. No positive outcomes are generally envisaged in this case. Finally, incongruence between company's brand image and self-image of consumers was observed mostly in the "Roller coaster" trajectory. Although brand usage is typically excluded for the future, reconciliation with the brand is desired in this case.

\section{Managerial implications}

From the managerial point of view, it is important for companies to be able to deal with brand hate in an effective way. As Kucuk (2008, p. 211) states, "brand hate directly and indirectly impacts consumers' perceptions of the targeted brand's identity and image, and consumer purchase decisions". Most recently, Kähr et al. (2016, p. 25) have argued that even “one single 
consumers can lead the brand to lose numerous existing customers and can alienate innumerable potential customers, which can result in millions of dollars of damage to a brand".

In that respect, the paper offers a series of insights. Generally, it shows that brand hate can be experienced by consumers in a variety of ways or trajectories. This suggests that companies first need to have adequate systems and mechanisms in place to capture brand haters. Once identified, it is crucial to understand the reasons for their hate as this gives crucial insights into how to deal with brand haters. For example, if hate is triggered by negative past experiences, there is a likelihood that this relationship can be "saved" if appropriate product or service recovery strategies are in place. So depending on the reason why consumers hate a brand, managers may identify different strategies to address such hate.

Specifically, managers should be interested in recovering the relationships that fall in the "Down-up" and "Roller coaster" trajectory types. Consumers in these trajectories hope to solve the existing conflicts with the brand and to maintain their relationships with them in the future. These relationships are still valuable for consumers, and have the potential to grow positively in the future. More difficult to recover are the relationships that were categorized as "Downward slope flattens" and "Steady decrease." In this case, consumers are detached from the brand and disinterested in the brand's conversations. However, as they are complaining with the company, managers could listen to these consumers carefully. If the relationships with them cannot be recovered, they may still manage to stop the negative effects (word-of-mouth) these consumers are spreading out. Finally, a divorce with consumers should be accepted if relationships fall in the "Negative all the way" type of trajectory. The company should accept that not all consumers agree with their vision and behavior, also in the light of the fact that these consumers do not seem harmful as do not massively adopt active hateful behaviors towards the brand. 


\section{Limitations and future research}

The current paper suffers from some limitations that may be overcome by future research. In the light of the importance of dynamic approaches to study social interactions and relationships (e.g., Latané, 1981), adopted for example to study brand love (Langner et al., 2016), this paper examined consumers' past, present, and future hate feelings towards brands as reported by consumers at a single point in time. Therefore, it is a cross-sectional study. Future research could adopt a longitudinal perspective (Rindfleisch et al., 2008), by following the development of consumers' hate feelings over time. Nevertheless, whether researchers conduct a cross-sectional or longitudinal study, each has advantages and disadvantages (Rindfleisch et al., 2008).

Another avenue for future research is to assess any difference of these trajectories to any kind of relationship that consumers build with brands. For example, one could study whether these are typical progressions that exist for any kind of relationships. Or one could adopt a quantitative approach and measure how the emotion of hate, as well as relevant marketing constructs such as brand attachment (Park et al., 2013), detachment (Perrin-Martinenq, 2004), and attitude, together with other consumption-related emotions (Richins, 1997; Romani et al., 2012), may change with the evolution of the hate story.

Future research could also further investigate the love-hate, or hate-love, relationship. It could understand if brand love and brand hate are the opposite of one another, or if they can coexist and under which conditions. Langner et al. (2016) already envisaged some intercorrelation between positive and negative feelings towards the brand. However, the complexity of this relation in terms of the ambivalent emotions felt by consumers towards a brand, and the 
conflicting behavior adopted, deserves further investigation in order to better reveal the underlying dynamics and processes.

Finally, future research could investigate how various product or service recovery strategies are effect or ineffective as related to the various antecedents and trajectories identified. 


\section{References}

Alba, J.W. and Lutz, R.J. (2013) Broadening (and narrowing) the scope of brand relationships. Journal of Consumer Psychology, 23(2): 265-68.

Albert, N., Merunka D. and Valette-Florence P. (2008) When consumers love their brands: exploring the concept and its dimensions. Journal of Business Research, 61(10): 1062-75.

Albert, N., Merunka, D. and Valette-Florence, P. (2013) Brand passion: antecedents and consequences. Journal of Business Research, 66(7): 904-909.

Batra, R., Ahuvia, A. and Bagozzi, R.P. (2012) Brand love. Journal of Marketing, 76(2): 1-16.

Bellenger, D.N., Steinberg, E. and Stanton, W.W. (1976) The congruence of store image and self image. Journal of Retailing, 52(Spring): 17-32.

Birdwell, A.E. (1968) A study of the influence of image congruence on consumer choice. Journal of Business, 41(January): 76-88.

Bryson, D., Atwal, G. and Hultén, P. (2013) Towards the conceptualisation of the antecedents of extreme negative affect towards luxury brands. Qualitative Market Research: An International Journal, 16(4): 393-405.

Carroll, B.A. and Ahuvia, A.C. (2006) Some antecedents and outcomes of brand love. Marketing Letters, 17(2): 79-90.

Fehr, B. and Russell, J. (1984) Concept of emotion viewed from a prototype perspective. Journal of Experimental Psychology, 113: 464-486.

Fetscherin, M. and Heinrich, D. (2014) Consumer brand relationships: a research landscape. Journal of Brand Management, 21: 366-71. 
Fetscherin, M., Boulanger, M., Gonçalves, C. and Quiroga S. (2014) The effect of product category on consumer brand relationships. Journal of Product and Brand Management, 23(2): 78-89.

Fournier, S. and Alvarez, C. (2013) Relating badly to brands. Journal of Consumer Psychology, 23(2): 253-64.

Grégoire, Y., Tripp, T.M. and Legoux, R. (2009) When customer love turns into lasting hate: the effects of relationship strength and time on customer revenge and avoidance. Journal of Marketing, 73(6): 18-32.

Hegner, S.M., Fetscherin, M. and van Delzen, M. (2017) Determinants and outcomes of brand hate. Journal of Product and Brand Management, 26(1): 13-25.

Johnson, A.R., Matear, M. and Thomson, M. (2011) A coal in the heart: self-relevance as a postexit predictor of consumer anti-brand actions. Journal of Consumer Research, 38(1): 108125.

Kähr, A., Nyffenegger, B., Krohmer, H. and Hoyer, W. D. (2016) When consumers wreak havoc your brand: the phenomenon of consumer brand sabotage. Journal of Marketing, 80(3): 166.

Kucuk, S. U. (2008) Negative double jeopardy: the role of anti-brand sites on the internet. Journal of Brand Management, 15: pp. 209-222.

Langner, T., Bruns, D., Fischer, A. and Rossiter, J.R. (2016) Falling in love with brands: a dynamic analysis of the trajectories of brand love. Marketing Letters, 27: 15-62.

Latané, B. (1981) The psychology of social impact. American Psychologist, 36(4), 343-356. Nunnally, J.C. (1978). Psychometric theory. New York: McGraw-Hill Publishing Company. 
Park, C.W., Eisingerich, A.B. and Park, J.W. (2013) Attachment-aversion (AA) model of customer-brand relationships. Journal of Consumer Psychology, 23(2): 229-48.

Perrin-Martinenq, D. (2004) The role of brand detachment on the dissolution of the relationship between the consumer and the brand. Journal of Marketing Management, 20(9-10): 100122.

Pichler, E. and Hemetsberger, A. (2007) "Hopelessly devoted to you" - Towards an extended conceptualization of consumer devotion. Advances in Consumer Research, 34: 194-199.

Richins, M.L. (1997) Measuring emotions in the consumption experience. Journal of Consumer Research, 24 (2): 127-146.

Rindfleisch, A., Malter, A., Ganesan, S. and Moorman, C. (2008) Cross-sectional versus longitudinal survey research: concepts, findings, and guidelines. Journal of Marketing Research, 45(3): 261-279.

Romani, S., Grappi, S. and Dalli, D. (2012) Emotions that drive consumers away from brands: measuring negative emotions towards brands and their behavioral effects. International Journal of Research in Marketing, 29(1): 55-67.

Romani, S., Grappi, S., Zarantonello, L. and Bagozzi, R. (2015) The revenge of the consumer! How brand moral violations lead to consumer anti-brand activism. Journal of Brand Management, 22(8): 658-672.

Rossiter, J.R. (2012) A new C-OAR-SE-based content-valid and predictively valid measure that distinguishes brand love from brand liking. Marketing Letters, 23(2): 905-16.

Rust, R.T. and Cooil, B. (1994) Reliability measure for qualitative data: theory and implications. Journal of Marketing Research, 31: 1-14. 
Shaver, P., Schwartz, J., Kirson, D.,and O’Connor, C. (1987) Emotion knowledge: further exploration of a prototype approach. Journal of Personality and Social Psychology, 52: 1061-1086.

Solomon, R.C. and Stone, L.D. (2002) On "positive" and "negative" emotions. Journal for the Theory of Social Behaviour, 32(4): 417-435.

Spears, N. and Singh, S. N. (2004) Measuring Attitude toward the Brand and Purchase Intentions. Journal of Current Issues \& Research in Advertising, 26(2): 53-66.

Sprott, J.C. (2004) Dynamical models of love. Nonlinear dynamics, psychology, and life sciences, 8(3):303-314.

Sternberg, R.J. (1986) A triangular theory of love. Psychological review, 93(2), 119.

Sternberg, R.J. (2003) A duplex theory of hate: development and application to terrorism, massacres, and genocide. Review of General Psychology, 7(3): 299-328.

Zarantonello, L., Romani, S., Grappi, S. and Bagozzi, R.P. (2016) Brand hate. Journal of Product \& Brand Management, 25(1): 11-25. 
Table 1. Hated brands

\begin{tabular}{|c|c|}
\hline $\begin{array}{c}\text { Product category } \\
\text { (N all mentions) }(N \text { most hated brand })\end{array}$ & $\begin{array}{c}\text { Brand names } \\
\text { (N all mentions) }(\boldsymbol{N} \text { most hated brand })\end{array}$ \\
\hline Apparel (29) (10) & $\begin{array}{l}\text { Abercombie \& Fitch (4) (2), Benetton (3) (1), Bershka (1) (0), Converse (1) (0), } \\
\text { Crocs (1) (1), Dondup (1) (1), Ed Hardy (1) (0), Fred Perry (1) (0), Geox (1) (0), } \\
\text { Guess (2) (0), H\&M (1) (1), Hollister (2) (0), Iceberg (1) (0), Intimissimi (1) (1), La } \\
\text { Martina (1) (1), Munich (1) (0), Navigare (1) (0), Nero Giardini (1) (0), Pompea (1) } \\
(1) \text {, Taglie Comode (1) (0), Urban Outfitters (1) (1), Zara (1) (0) }\end{array}$ \\
\hline Automotive (8) (5) & $\begin{array}{l}\text { Alfa Romeo (1) (0), BMW (1) (0), Fiat (1) (1), Mercedes (1) (1), Peugeot (1) (1), } \\
\text { Seat (1) (1), Toyota (1) (1), Volkswagen (1) (0) }\end{array}$ \\
\hline Beverages (7) (1) & $\begin{array}{l}\text { Evian (2) (0), Highland Spring (1) (0), Lavazza (1) (0), Parmalat (1) (0), Pepsi (1) } \\
(0) \text {, Redbull (1) (1) }\end{array}$ \\
\hline Electronics $(3)(0)$ & Ariston (1) $(0)$, Brown (1) $(0)$, Sony $(1)(0)$ \\
\hline Energy (5) (3) & BP (4) (3), Gasprom (1) (0) \\
\hline Financial services $(1)(1)$ & $\operatorname{EBA}(1)(1)$ \\
\hline FMCG (25) (2) & 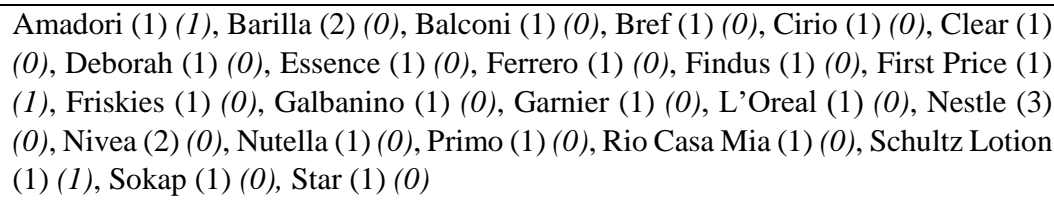 \\
\hline Luxury (15) (1) & $\begin{array}{l}\text { Armani (2) (0), Breil (1) (0), Dodo (1) (0), Dolce \& Gabbana (3) (1), Gucci (2) (0), } \\
\text { Hogan (2) (0), Louis Vuitton (2) (0), Moncler (1) (0), Tod's }(1)(0)\end{array}$ \\
\hline Media (3) $(0)$ & Armando Curcio Editore $(1)(0)$, New Yorker $(1)(0)$, Sky $(1)(0)$ \\
\hline Restaurants (11) (2) & $\begin{array}{l}\text { Burger King (1) (0), Fratelli La Bufala (1) (0), KFC (1) (0), McDonald's (6) (2), } \\
\text { Starbucks (2) (0) }\end{array}$ \\
\hline Retails (5) (3) & $\begin{array}{l}\text { Bodyshop (1) (0), Kiko (1) (0), My Décor (1) (1), Mondo Convenienza (1) (1), } \\
\text { Walmart (1) (1) }\end{array}$ \\
\hline Sporting goods (4) (2) & Adidas (1) (0), Londsdale (1) (1), Nike (1) (0), Sports Direct (1) (1) \\
\hline Technology (15) (8) & $\begin{array}{l}\text { Acer (1) (0), Apple (5) (2), Facebook (1) (0), Logitech (1) (1), Microsoft (1) (1), } \\
\text { Samsung (6) (4) }\end{array}$ \\
\hline Telecommunications (13) (9) & $\begin{array}{l}\text { Fastweb (2) (2), Jumbo (1) (1), Rogers (1) (1), Tele } 2 \text { (1) (1), Telecom (2) (1), } \\
\text { Vodafone (1) (1), Wind (5) (2) }\end{array}$ \\
\hline Tobacco $(2)(0)$ & Lucky Strike (1) $(0)$, Marlboro (1) $(0)$ \\
\hline Transportation (12) (5) & $\begin{array}{l}\text { Alitalia (1) (1), British Airways (1) (0), Easyjet (2) (1), First Bus Company (1) (0), } \\
\text { Frecciarossa (1) (1), Ryanair (6) (2) }\end{array}$ \\
\hline Travel $(2)(0)$ & Alpitour $(1)(0)$, Eden Viaggi $(1)(0)$ \\
\hline Other (6) (1) & $\begin{array}{l}\text { Boero (1) (0), Fitness First (1) (0), Mitchell (1) (1), Moleskine (1) (0), Rayban (1) } \\
(0) \text {, Republican Party (1) (0) }\end{array}$ \\
\hline
\end{tabular}




\section{Figure 1. The trajectories of brand hate ${ }^{1}$}

Trajectory type 1: "Negative all the way"

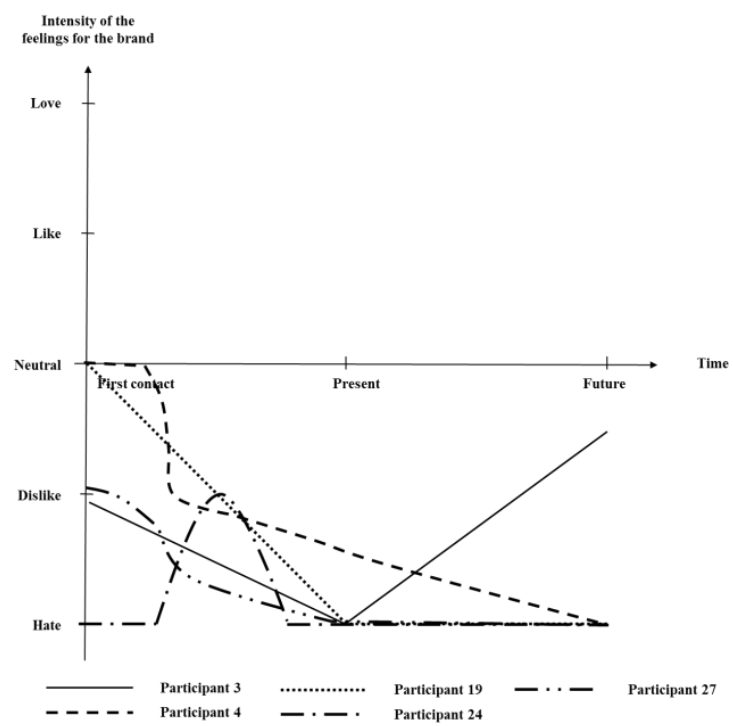

Trajectory type 3: "Downward slope flattens"
Trajectory type 2: "Down-up"

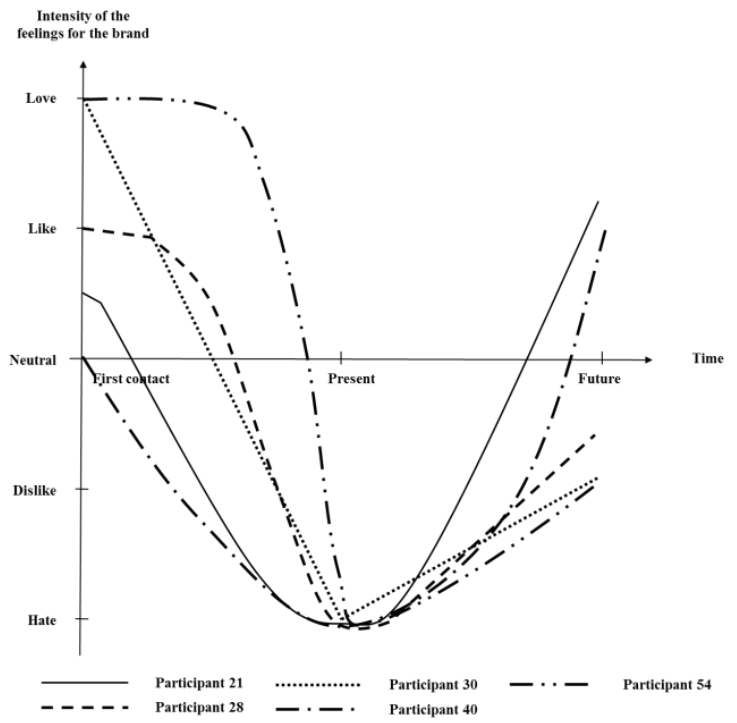

Trajectory type 4: "Roller coaster"

${ }^{1}$ Note that, for clarity purposes, for the trajectories types 1,2,3, and 4 we reported a maximum of five trajectories. All other trajectories are available from the
authors upon request. 

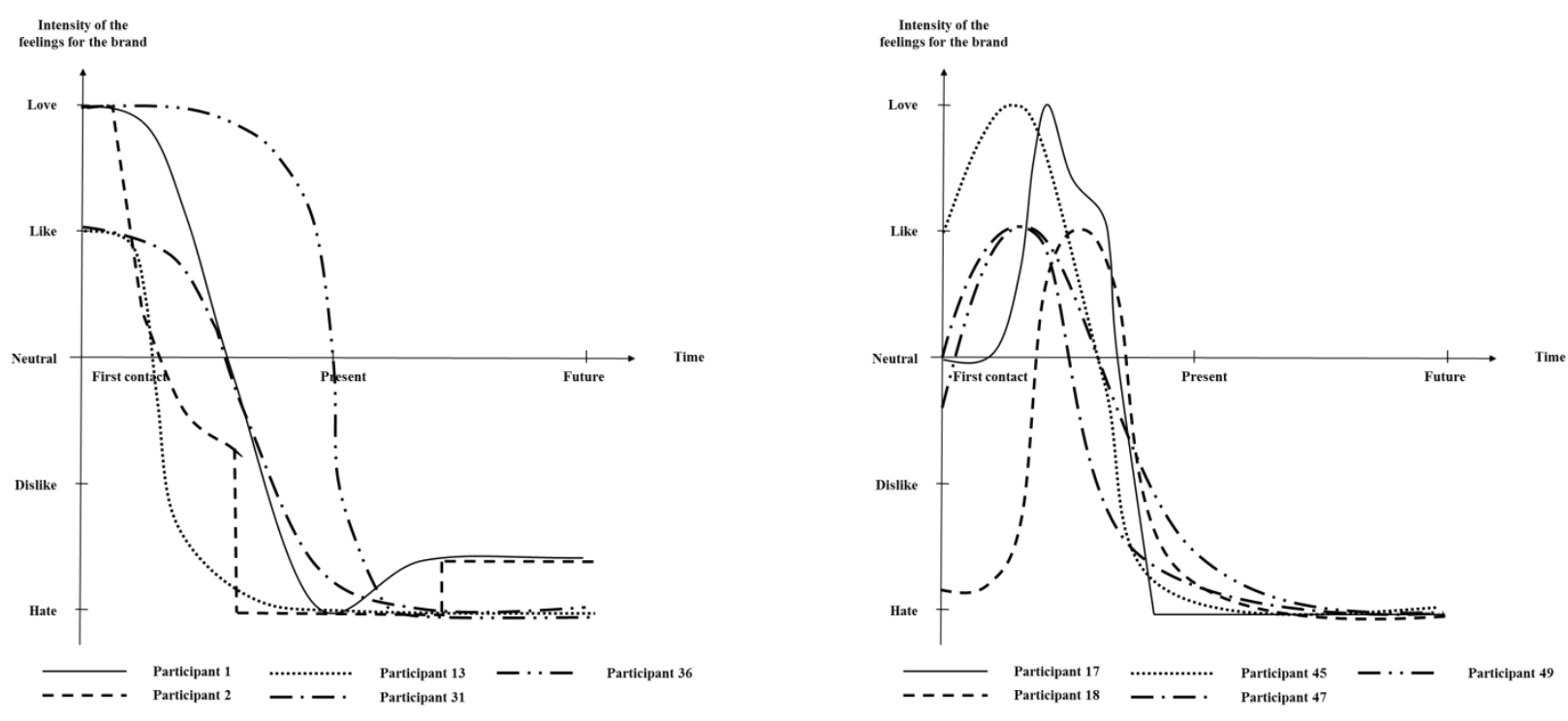

Trajectory type 5: "Steady decrease"

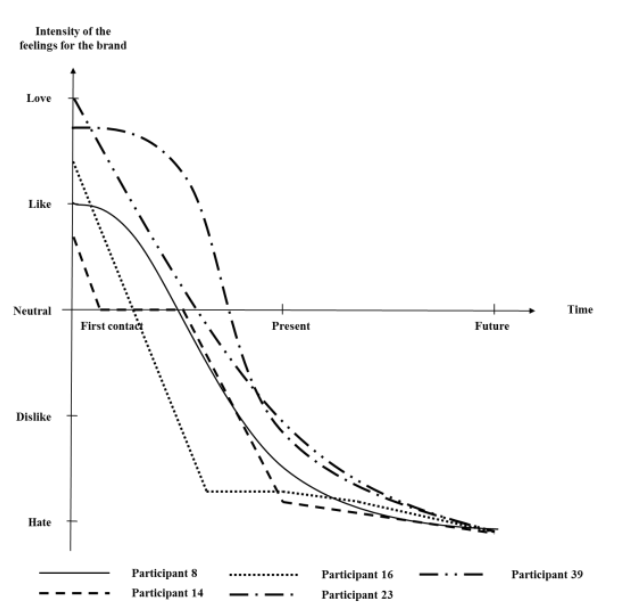




\section{Appendix A. Summary of most relevant studies on brand hate}

\begin{tabular}{|c|c|c|c|c|c|}
\hline & $\begin{array}{l}\text { Nature of work } \\
\text { ( } \mathbf{E}=\text { empirical; } \\
\mathbf{C}=\text { conceptual) }\end{array}$ & $\begin{array}{l}\text { Conceptualization / } \\
\text { measurement of hate }\end{array}$ & Antecedents & Outcomes & $\begin{array}{l}\text { Mediator / } \\
\text { moderator }\end{array}$ \\
\hline $\begin{array}{l}\text { Grégoire et al. } \\
\text { (2009) }\end{array}$ & $\mathrm{E}$ & $\begin{array}{l}\text { Desire for revenge and desire } \\
\text { for avoidance }\end{array}$ & - & $\begin{array}{l}\text { Need to punish and cause } \\
\text { harm to firms, } \\
\text { need to withdraw from } \\
\text { interactions with the firm }\end{array}$ & - \\
\hline $\begin{array}{l}\text { Johnson et al. } \\
(2011)\end{array}$ & $\mathrm{E}$ & Mainly as consumer revenge & - & Anti-brand actions & Emotion of shame \\
\hline Romani et al. (2012) & $\mathrm{E}$ & Part of dislike & - & $\begin{array}{l}\text { Complaining, negative } \\
\text { word-of-mouth, and brand } \\
\text { switching }\end{array}$ & - \\
\hline Bryson et al. (2013) & $\mathrm{E}$ & $\begin{array}{l}\text { Intense negative emotional } \\
\text { affect towards the brand }\end{array}$ & $\begin{array}{l}\text { Brand's country of origin, } \\
\text { consumer dissatisfaction, } \\
\text { negative stereotypes of a } \\
\text { brand's consumers, and } \\
\text { corporate social } \\
\text { performance }\end{array}$ & - & - \\
\hline $\begin{array}{l}\text { Alba and Lutz } \\
(2013)\end{array}$ & $\mathrm{C}$ & True brand disgust & $\begin{array}{l}\text { High switching costs, a } \\
\text { local monopoly, or some } \\
\text { other manifestations of exit } \\
\text { barriers }\end{array}$ & $\begin{array}{l}\text { Consumer's frustration via } \\
\text { social media, postings on } \\
\text { hate sites on the Internet, } \\
\text { and communicating } \\
\text { negative affect in daily } \\
\text { interactions with other } \\
\text { consumers }\end{array}$ & - \\
\hline Romani et al. (2015) & $\mathrm{E}$ & Disgust, anger/fear, contempt & $\begin{array}{l}\text { Perceptions of moral } \\
\text { violations by brand parent } \\
\text { company }\end{array}$ & Anti-brand activism & $\begin{array}{l}\text { Consumer } \\
\text { empathy }\end{array}$ \\
\hline $\begin{array}{l}\text { Zarantonello et al. } \\
\text { (2016) }\end{array}$ & $\mathrm{E}$ & $\begin{array}{l}\text { Constellation of negative } \\
\text { emotions towards the brand, } \\
\text { including anger, contempt, } \\
\text { disgust, fear, disappointment, } \\
\text { shame, and dehumanization }\end{array}$ & $\begin{array}{l}\text { Corporate wrongdoings, } \\
\text { violation of expectations, } \\
\text { and } \\
\text { taste systems }\end{array}$ & $\begin{array}{l}\text { Negative WOM, consumer } \\
\text { complaining, protest } \\
\text { behaviors, and patronage } \\
\text { reduction or cessation }\end{array}$ & - \\
\hline
\end{tabular}


More intense emotional

response towards a brand than

brand dislike
Past experience, symbolic

incongruence, and

ideological incompatibility
Brand avoidance, negative

word-of mouth, and brand

retaliation 